\title{
A Synthesis of Current Approaches to Traps Is Useful But Needs Rethinking for Indigenous Disadvantage and Poverty Research
}

\author{
Yiheyis T. Maru ${ }^{1}$, Cameron S. Fletcher ${ }^{1}$, and Vanessa H. Chewings ${ }^{1}$
}

\begin{abstract}
Indigenous disadvantage and poverty have persisted and are set to continue into the future. Although a large amount of work describes the extent and nature of indigenous disadvantage and poverty, there is little evidence-based systems understanding of the mechanisms that keep many indigenous people in their current dire state. In such a vacuum, policy makers are left to make assumptions about the causal mechanisms. The persistence of inequality and poverty suffered by indigenous people is broadly consistent with the existence of dynamical traps as described in both the resilience and development literature. We reviewed and synthesized these bodies of literature on traps and found that although they give a good lead to a systemic and parsimonious way of exploring traps, the mechanisms suggested need significant rethinking for the indigenous context. Specifically, we recommend extending the concept of traps to encompass the possibility that they are highly resilient but undesirable states, in contrast to current notions of traps as low resilience states. We also highlight the need for close scrutiny of the boundaries of indigenous systems because of the historically public nature of indigenous lives as well as the possible conjoint existence and causal linkage between poverty- and rigidity-traps in the indigenous context.
\end{abstract}

Key Words: developments, indigenous disadvantage, poverty traps, resilience, rigidity traps

\section{INTRODUCTION}

Indigenous people in different countries of the world are invariably disproportionately represented among the poor. Estimates of the number of indigenous vary from 250-350 million living in more than 70 countries and forming more than 5000 distinct groups. According to one estimate they make up $15 \%$ of the world's poor but only about $5 \%$ of the world's population (IWGIA 2008). In China, indigenous people are 1.5 times as likely to be poor than nonindigenous, and poverty rates up to $80 \%$ of indigenous populations are reported for Africa, South America, Latin America, and Mexico (Hall and Patrinos 2010).

High levels of poverty and disadvantage among indigenous people are also reported in highly developed countries, particularly Australia, Canada, and the United States of America (Young 1995, Eversole et al. 2005, Hall and Patrinos 2005). In all three countries, indigenous poverty and disadvantage have been not only deep and widespread but persistent, defying policy prescriptions to close the socioeconomic gaps between indigenous people and their counterpart nonindigenous groups (Cornell 2005, Eversole et al. 2005, Hall and Patrinos 2010). Indigenous Canadians are still among the poorest with no sign of significant improvement in income inequality with their nonindigenous counterparts (Wilson and MacDonald 2010). More than onequarter of the American Indian and Alaskan Native population is living in poverty, a rate that is more than double that of the general population (Sarche and Spicer 2008, Lewis and BurdSharps 2010).

A comparable recent estimate for Australia tells of a more pronounced disparity between indigenous and nonindigenous peoples. In 2008, Australia was ranked second out of 182 countries with a Human Development Index (HDI) score of 0.968 (UNDP 2009), but a separate calculation for Australia's indigenous population estimated a 0.737 HDI score, slightly higher than the Syrian Arab Republic and the Occupied Palestinian Territories, but slightly lower than Fiji and Sri Lanka (Yap and Biddle 2010). Indigenous Australians also suffer chronic socioeconomic and health disadvantages (Australian Institute of Health and Welfare 2008). The 2011 report Overcoming Indigenous Disadvantage (SCRGSP 2011) notes significant disparities across several well-being indicators including rates of child mortality, teenage birth, chronic disease, education, employment, and imprisonment that have not changed since at least the start of reporting in 2003. These disparities are persistent despite a decade of sustained Australian economic prosperity and government efforts to close the gap for indigenous Australians (SCRGSP 2011), and many indicators are expected to continue diverging for the next 100 years (Altman et al. 2009).

This persistence of both inequality and poverty among indigenous people strongly suggests the existence of multiple well-being equilibria that are maintained by poverty and rigidity traps (Maru and Chewings 2011). Poverty traps are self-reinforcing feedback loops that keep social-ecological systems in persistent poverty (Azariaidis and Stachurski 2005, Dasgupta 2007). Rigidity traps refer to inflexibility in socialecological systems because of high and self-reinforcing connections between institutions and networks of agents with high access and holding of resources (Holling 2001, Holling and Gunderson 2002). Traps make the outcomes from efforts aimed at closing poverty and inequality gaps nonlinear affairs. 
Understanding the factors and processes that create and maintain these traps is fundamental to finding effective pathways for escape from persistent inequality and poverty.

Noting the current limited and fragmentary efforts on causal analysis, Maru and Chewings (2011) have called for a systems research agenda on trap mechanisms that will adequately explain the persistence of indigenous inequality and poverty. This paper is a first attempt to address this call. It reviews and synthesizes the development and resilience literature that have separately developed theoretical and empirical understandings of trap mechanisms, primarily from studies on developing countries and among African Americans. It will also highlight insights and identify challenges in applying the concept and analysis of traps in the indigenous context, especially in welldeveloped countries.

Although lessons from the review and synthesis of the literature will have broader applicability, the emphasis on indigenous people in developed countries helps us focus on challenges that arise from this context. Indigenous people in highly developed countries such as Australia, Canada, and the United States have been subjected to colonial settler cultures that have significantly disrupted their traditional cultures and livelihoods (Moran 2002). Indigenous cultures, as distinct from other disadvantaged groups, have suffered substantial population decline, enormous resource losses, social organization, and subjection to a battery of assimilation policies (Armitage 1995, Cornell 2005). Despite the high development ranking of these countries, their indigenous peoples still live in stark contrast of poverty and disadvantage to their nonindigenous counterparts. They continue to struggle to maintain their language, culture, and way of life (Altman 2000). Poverty and inequality are tightly linked in these indigenous contexts and inequality is horizontal, in that it follows social group contours, making escape from poverty harder because of group-level barriers (Stewart 2009).

We review the development and resilience literature that has separately developed theoretical and empirical understandings of poverty and rigidity traps. We synthesize the two bodies of literature, highlighting insights and identifying the challenges we may face in beginning to apply the concept and analysis of traps in the indigenous context. Finally, we provide concluding remarks on the importance of further systemsbased work to the synthesis of trap concepts, including mechanisms, approaches, and system boundaries, and consider insights and challenges from the indigenous context.

\section{REVIEW}

There are two main bodies of literature on traps: development and resilience. In the development literature, several mechanisms are proposed as causing poverty traps including various economic thresholds (e.g., Azariadis and Stachurski 2005), dysfunctional institutions (e.g., Engerman and Sokoloff 2006, Hoff and Sen 2006), neighborhood effects (e.g., Sampson and Morenoff 2006), and intergenerational transmission of poverty (e.g., Bird 2007). The literature on resilience also proposes the poverty trap as one of the departures from a normal adaptive cycle of a system (Holling and Gunderson 2002, Carpenter and Brock 2008). The adaptive cycle refers to a model of phases of change of a system. In the case of a poverty trap, low potential (capital), low connectedness (network and institutions), and low general system resilience lead to a loss of adaptive capacity of the system (Holling 2001). The resilience literature also introduces the concept of a rigidity trap, i.e., system inflexibility that prevents successful adaptation to internal demands and changes in the environment. The rigidity trap concept is an essential contribution to the synthesis of these two bodies of literature.

\section{Poverty traps in the development literature}

In the development literature, the phrase poverty trap refers to a self-reinforcing mechanism that causes poverty to persist (Azariaidis and Stachurski 2005). The origin of contemporary poverty trap theory is often traced back to work done in the 1950s. Nurkse (1953), building on work by Young (1928), studied the possibilities for economic growth in underdeveloped countries, investigating notions of circular and cumulative causation driving a vicious cycle of poverty, which were further developed by Myrdal (1957). Coordinated and complementary investments in industrialization, delivering a "big push" for growth, were suggested as a solution to the vicious cycle for underdeveloped nations (Nurkse 1953, Rosenstein-Rodan 1984).

This understanding of the complementary and circular nature of causal processes, or positive feedback loops, involved in both economic decline and growth led to the recognition of the existence of thresholds and multiple equilibria. This contrasts with classical economic growth models that predict that given time and effort the growth paths of poor countries will converge toward a single equilibrium of the prosperity of the rich countries (Barrett and Swallow 2006). In reality, increasing returns only set in after a nation has achieved a particular threshold level of output per capita. Poor countries get caught in a poverty trap because they have been hitherto unable to push themselves above these economic thresholds. Poverty traps are not restricted to nations, but can also apply to individuals, households, or a group of people within developing and developed nations, although the dynamics of these traps will differ at each scale. Bowles et al. (2006) usefully organized these mechanisms into three broad categories: critical thresholds, dysfunctional institutions, and neighborhood effects.

Critical thresholds are often linked with levels of complementary capital that can accelerate growth. In a poverty trap, despite efforts, individuals, groups, or nations fail to raise or lack access to threshold levels of the different capital that 
spur economic growth and well-being, including human, financial, physical, and natural capital (Barrett and Swallow 2006). Thresholds can exist in both individual capital and combinations of capital: if physical and natural capital are both scarce, much effort may be needed to cook a meal or heat a hearth, reducing available human capital. In some cases, these complementary processes can create a feedback loop sufficient to trap an individual, a household, and a community. Primary education, nutritional intake, and health care are complementary inputs in child development. A failure to have an adequate nutritional intake affects health, and both of these affect performance in education, leading to poor child development and human capital that will affect lifetime productivity (Dasgupta 2007).

The capital threshold perspective has been well elaborated and implemented to analyze poverty traps in Africa (Carter and May 1999, 2001, Carter and Barrett 2006, Barrett and Swallow 2006). Figure 1 is reproduced from Barrett and Swallow (2006), and represents well-being dynamics under the poverty trap hypothesis. It represents how the well-being at one point in time creates the conditions for well-being in the future, through the internal dynamics of various capital by which the illustrated socioeconomic system evolves. The final outcome is that a poor individual, community, or nation trapped near $\mathrm{W}_{\mathrm{L}}$ can only escape to the sustainable state of higher wellbeing at $\mathrm{W}_{\mathrm{H}}$ with well-coordinated external support that increases well-being beyond $\mathrm{W}_{\mathrm{C}}$. Any less and its internal processes will eventually cause it to collapse back to $\mathrm{W}_{\mathrm{L}}$, the very definition of a poverty trap.

Fig. 1. Represents well-being dynamics under the poverty trap hypothesis, reproduced from Barrett and Swallow (2006) with permission from Elsevier.

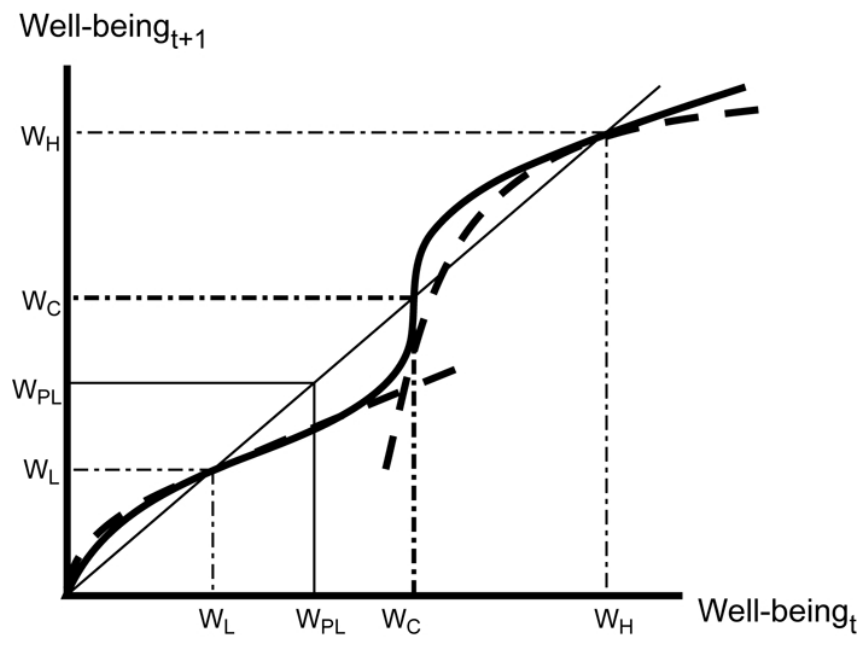

Dysfunctional institutions refer to maladaptive or at times perverse rules and norms that dominate and govern economic and social behavior and the actions of individuals, groups, and societies (Bowels et al. 2006). They are a set of interacting extractive institutions that reward activities such as rent seeking, corruption, and predation on the production of others. Institutions can initiate and sustain the impoverishment of groups or even an entire society. Customary institutions, such as a kin system, that have traditionally served a community as a safety net, can sometimes become maladapted and trapping when in extensive contact with a market economy and institutions (Hoff and Sen 2006). Similarly, institutions that lead to and maintain deep political and economic inequality can create widespread and persistent poverty (Engerman and Sokoloff 2006).

Neighborhood effects capture the social and geographic clustering of persistent poverty and disadvantage. They refer to the multiple effects that some poor neighborhoods have on well-being, over and above the disadvantages associated with growing up in a poor family (Leventhal and Brooks-Gunn 2000, Sampson et al. 2002). Thus, poor neighborhoods often have worse schools, child care, and health services, which can be easily overwhelmed by the needs of poor families. Poor neighborhoods are more likely than rich neighborhoods to become sites for concentrated poor health status, lagging school performance, behavior problems, substance abuse, early sex and parenthood, delinquency, and violence. Destitute families and even groups can pass poverty on to their children. Intergenerational poverty transmission is the strongest form of persistent poverty (Bird 2007). Poverty that spans generations can be seen as both a characteristic and a cause of chronic poverty (Wilson 1987, Leventhal and Brooks-Gunn 2000, Pebley and Sastry 2004).

Mechanisms that create poverty traps can also occur across multiple social and spatial scales: from individuals, to families, communities, regions, and a country or countries. Barrett and Swallow (2006) named these patterns of low-level dynamic equilibria that exist simultaneously at multiple scales, i.e., micro, meso, and/or macro, as fractal poverty traps. These low-level multiple equilibria are self-reinforcing through feedback effects. Barrett and Swallow (2006) give an example of such a phenomenon in the case of some developing countries where financial constraints often exist at multiple scales. Individuals and households are unable to access credit because of insufficient collateral; local governments are unable to borrow on capital markets because of limited tax collection capacity; and national governments are rationed out of global financial markets because of political risk or debt. Where such constraints exist at multiple levels, they become interdependent.

\section{Traps in the resilience literature}

In the resilience literature, change in social-ecological systems is theorized in terms of an adaptive cycle consisting of four phases: exploitation; conservation; release; and reorganization 
(Table 1; Holling 2001, Holling and Gunderson 2002, Allison and Hobbs 2004). In addition, any 'focal system' is nested in a loose hierarchy of systems at different scales, called panarchy, each undergoing interlinked adaptive cycles. Each scale operates at its own pace, protected from above by slower, larger levels, but invigorated from below by faster, smaller cycles of innovation. However, during the release and reorganization phases, critical cross-scale interactions can occur that can lead to "revolt" connections, in which release phase collapse on one scale triggers a crisis one level up, and "remember" connections, in which the reorganization phase of a cycle is organized by a higher level accumulation phase (Holling 2001).

Table 1. The level of potential, connectedness, and resilience in the four phases of the adaptive cycle. In the exploitation phase, potential and connectedness are low but resilience is high. In conservation, resilience decreases while the other values increase. Eventually, some internal or external perturbation triggers the release phase, in which potential crashes. Finally, in the reorganization phase, resilience and potential grow, connectedness falls, unpredictability peaks, and new system entrants can establish themselves (Source: Allison and Hobbs 2004).

\begin{tabular}{lccc}
\hline \hline Phase & Potential & Connectedness & Resilience \\
\hline Exploitation & Low & Low & High \\
Conservation & High & High & Low \\
Release & Low & High & Low \\
Reorganization & High & Low & High \\
\hline
\end{tabular}

The adaptive cycle theory proposes that three fundamental properties of a system shape the systems dynamics through its adaptive cycle: (1) potential, which determines the range of future options possible; (2) connectedness, which determines the system's ability to modulate external variability; and (3) adaptive capacity or general system resilience, a measure of vulnerability to unexpected shocks that can break a system's internal controlling processes (Holling 2001).

In this broad sense, departures from the adaptive cycle, as is the case in poverty and rigidity traps, are noted as maladaptive states (Holling 2001, Holling et al. 2002). In a particular system configuration, traps are created by undesirable lock-in states of systems driven by self-stabilizing feedback loops (Scheffer and Westley 2007). Therefore, specific traps can arise as a result of certain configurations of the levels of the three fundamental variables: potential, connectedness, and adaptive capacity that are different from those combinations in each of the four phases of the adaptive cycle. Table 2 shows four unique configurations of the essential systems properties thought to lead to maladaptive or pathological states.
Table 2. The level of each of the three variables that characterize the four maladaptive states (Source: Allison and Hobbs 2004).

\begin{tabular}{lccc}
\hline \hline Maladaptive state & Potential & Connectedness & Resilience \\
\hline Poverty trap & Low & Low & Low \\
Rigidity trap & High & High & High \\
Lock-in trap & Low & High & High \\
$?^{\dagger}$ & High & Low & Low \\
\hline${ }^{\dagger}$ a theoretical configuration not yet mapped to an observation. & \\
\end{tabular}

An example of a poverty trap is the state of chronic destitution in sub-Saharan countries where potential is lost because of misuse of resources and external forces and societies continue to exist in an impoverished state of bare subsistence. The rigidity trap is exemplified by hierarchies, such as large bureaucracies (Holling et al. 2002), societies that operate under rigid and apparently immutable caste systems, and in regions of the developing world that have abundant natural resources but are subject to the rigid control of corrupt political regimes.

The understanding of traps and the adaptive cycle has been further refined by focusing on adaptive capacity, a central feature of the general resilience of a system, which is one of the three critical properties of systems. Carpenter and Brock (2008) have developed an adaptive-capacity model based on the physiological notion of allostasis (Sterling 2004). The theory of allostasis proposes that organisms maintain stability and survive by varying vital physiological parameters, such as body temperature and blood pressure to accommodate for varying internal and external demands. In allostasis, the brain plays a central coordination role and can override local negative feedback mechanisms to impose new set points for vital parameters in response to anticipated or existing external demands. This is in contrast to the notion of homeostasis where the survival of organisms is predicated on maintaining a constant value of certain vital parameters through negative feedbacks of physiological regulatory mechanisms, despite fluctuating external factors.

Analogous to allostasis in physiology, Carpenter and Brock (2008) define adaptive capacity as the ability of a socialecological system to adjust to changing internal demands and external circumstances. They use a bell-shaped function to elaborate a minimal model of the adaptive capacity of a system, $\mathrm{A}(\mathrm{S})$, as a function of stress, $\mathrm{S}$, reproduced in Figure 2.

Stress refers to the cumulative effort exerted to adapt with internal and external demands. The model has double thresholds that result in three regions: a poverty trap, associated with lower stress, i.e., lower cumulative effort exerted than that required to adapt; an adaptive range; and a rigidity trap, associated with higher stress, i.e., higher cumulative effort exerted than that required to adapt. They 
Table 3. A summary of characteristics of trap conceptualization and mechanisms in the literature.

\begin{tabular}{|c|c|c|}
\hline Trap characteristics and challenges for synthesis & Development literature & Resilience literature \\
\hline Poverty traps interpretation & $\begin{array}{l}\text { Self-reinforcing mechanisms that cause poverty to } \\
\text { persist }\end{array}$ & $\begin{array}{l}\text { Maladaptive departures from normal adaptive } \\
\text { cycle of system }\end{array}$ \\
\hline Poverty trap mechanisms & $\begin{array}{l}\text { 1) capital thresholds } \\
\text { 2) dysfunctional institutions, or } \\
\text { 3) neighborhood effects }\end{array}$ & $\begin{array}{l}\text { A system configuration of low potential, low } \\
\text { connectedness, and low resilience that locks a } \\
\text { system in a maladaptive state }\end{array}$ \\
\hline Rigidity traps & No explicit treatment & $\begin{array}{l}\text { A maladaptive configuration of high potential, } \\
\text { high connectedness, and high resilience. A social } \\
\text { system where members of an organization and } \\
\text { their institutions become highly connected, rigid, } \\
\text { and inflexible }\end{array}$ \\
\hline Strengths & $\begin{array}{l}\text { Detailed, specific, and mainly empirical } \\
\text { understanding of traps }\end{array}$ & $\begin{array}{l}\text { Broad, general, and mainly theoretical } \\
\text { understanding }\end{array}$ \\
\hline Weakness & $\begin{array}{l}\text { Separate, unconnected explanations } \\
\text { Neglect of ecological drivers }\end{array}$ & $\begin{array}{l}\text { Inconsistent treatment of traps } \\
\text { Tendency to endogenize causation } \\
\text { Limits of biological models }\end{array}$ \\
\hline Challenges vis à vis indigenous context & $\begin{array}{l}\text { The need for close scrutiny of system boundaries, } \\
\text { and accounting for internal and external factors } \\
\text { The need to reinterpret poverty traps as resilient but } \\
\text { The possibility of co-occurrence of poverty and rigi }\end{array}$ & $\begin{array}{l}\text { haracterization of system-environment interaction, } \\
\text { undesirable states } \\
\text { dity traps }\end{array}$ \\
\hline
\end{tabular}

Fig. 2. Adaptive capacity: $A(S)$ as a function of cumulative stress, S, reproduced from Carpenter and Brock (2008) with permission.

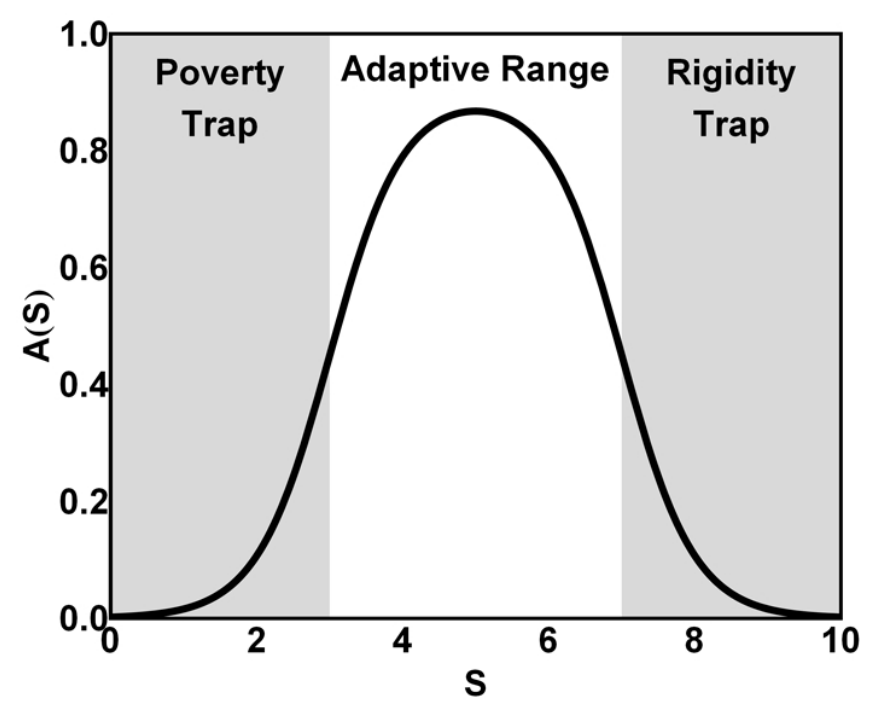

identify obesity and hypertension as examples of poverty and rigidity traps, respectively. Underused physiological systems wither, whereas physiological systems that are chronically used outside the normal operating range become rigid and incapable of responding appropriately to changing environments. Notice that here, both poverty and rigidity traps are characterized by low levels of adaptive capacity, a core aspect of general system resilience, albeit arising through different mechanisms: chronic under- and over-use of the system. This is in contrast to the earlier characterization of a rigidity trap with high specific resilience against actions designed to change the state of the system (see Table 2). Carpenter and Brock (2008) also identify a range of other system characteristics that can contribute to the balance between optimal stress response to maintain high adaptive capacity; including the heterogeneity of entities, how tightly they are connected by social networks and institutions, the capacity of the system to both focus resources and explore new scenarios, and the resulting ability of the system to dissipate stress.

\section{SYNTHESIS}

Both the development and resilience literature have a similar broad interpretation of a poverty trap, a system stuck in a poor state of affairs for a long time despite efforts to escape. However, there is a difference in the concepts and interpretations of poverty traps emphasized by each body of literature. Although the development literature focuses on the persistence of the poor state, the resilience literature focuses on the failure of the adaptive cycle or general resilience of the system. Each perspective has its own strengths and weaknesses as summarized in Table 3 , but by synthesizing ideas from both bodies of literature we can achieve a greater understanding than either literature alone. 
The strength of the development literature is that it provides detailed and, in some cases, empirically supported explanations of poverty traps. The weakness is that these explanations tend to be focused along existing disciplinary lines, and are therefore disparate. Although disciplinary factors such as economic growth (Collier 2007), governance structure (Hyden 2007), capital thresholds, dysfunctional institutions, or neighborhood effects (Bowles et al. 2006) may each be sufficient to cause a poverty trap, many of these factors seem to occur in tandem and interact in feedback loops influencing each other over time. A neighborhood with concentrated poverty can be both the result of and a site for maladaptive institutions. Neighborhoods with concentrated poverty are also less likely to have access to critical levels of the different types of capital necessary for escaping poverty. There have been attempts to describe the breadth of the different development related poverty trap mechanisms (Bowles et al. 2006, Kates and Dasgupta 2007). However, there is still a need for an overarching framework that spans the development and resilience literature and allows investigation of the possible existence and interaction of the different trap mechanisms in different poverty contexts.

To date, the development literature on poverty traps has largely seen poverty as a socioeconomic problem, and has therefore provided insufficient consideration of the contribution of ecological variables (Dasgupta 2007). This makes it difficult to consider the impacts and vulnerabilities to new types of global perturbations such as climate change. However, uncertainties that are generated by interactions between climatic and ecological factors may be essential in and of themselves in poverty trap dynamics. Elsewhere, the development literature does consider ecological and climatic issues, but these issues are not well linked into the poverty trap discussion. For example, the idea that poor people have multiple coping or adaptive mechanisms to climatic variability and ecological change, and that adaptation can be negative or positive is widely, but separately, discussed in the poverty and development literature (e.g., Davies 1996). There has also been a tradition of powerful socio-political approaches to the vulnerability of poor people to natural hazards that has similarly neglected biophysical factors (Adger 2006). The poverty trap literature could benefit from current interdisciplinary approaches that treat vulnerability as emergent from interactions of socioeconomic and biophysical factors rather than as an inherent socioeconomic property (for example, Brooks 2003, Turner et al. 2003, Adger 2006).

One of the strengths of the resilience literature is that it provides broad theoretical explanations of poverty traps, although it could benefit from the empirical approaches, detail, and disciplinary insight provided by the development literature. The resilience literature also proposes configurations of the core properties of a system that can give rise to a rigidity trap that has relevance to the indigenous context. No directly matching concept has been articulated in the development literature although Scheffer and Westley (2007) have identified some economic and management concepts, such as the "sunk-cost effect" and "group think," that display properties of rigidity traps. However, the development literature contains detailed political analysis of the interactions between historical colonial and indigenous systems that could provide rich detail missing from the concepts of rigidity traps in the resilience literature.

Although the resilience literature provides a general hypothesis of poverty and rigidity traps, it has two major weaknesses. The first is that the initial proposition of poverty traps as maladaptive configurations of low potential, low connectedness, and low general system resilience, or capacity for adaptation, is too broad and untested. The work by Carpenter and Brock (2008) is the only serious attempt to develop a more elaborate general traps hypothesis underpinned by a biological model. Although an improvement in terms of developing a simplified model of traps as a function of adaptive capacity, this model has its own significant limitations. First, it still needs to clarify some inconsistencies with its predecessor general traps propositions. Although the original typology of maladaptive configurations identifies a rigidity trap as having high resilience, in the allostasis-based model it is characterized as having low adaptive capacity, a core aspect of general system resilience (Carpenter and Brock 2008). The model also identifies a poverty trap as untapped potential, which seems to contradict the original conception of a poverty trap as having low potential in its core property configuration. Although these confusions are, perhaps, a reflection of the distinction between the general resilience of an entire system and the resilience of a specific state within a system, they will need clarification before this perspective can be applied more broadly.

Second, the biological basis of the allostasis model is not comprehensive enough to account for socio-political characteristics of a social-ecological system in persistent poverty. For example, not only under-use but also over-use of the resource system (natural capital) can lead to poverty traps in social-ecological systems. Furthermore, the functional and organizational connections between individuals and groups in a society, although important, may not be as tight and vital as those among organs and systems in an organism. In a society, individuals and groups can function independently and promote interests at the expense of others. Although a continued, extremely disproportionate allocation of resources to different organs can be fatal to an organism, a similarly disproportionate allocation of resources in social-ecological systems may not mean an end to the system. Rather, they may lead to the persistent poverty of many and the riches of a few.

Third, the allostasis model has tended to endogenize the causation of the poverty traps. The model focuses on the 
internal dynamics of traps and thus identifies under- and overuse of parts of the whole system as a cause of these pathological states. In contrast to these proximate causes, Sterling (2004), in formulating the theory of allostasis, locates ultimate causes for physiological traps in the environment.

In summary, the resilience literature can provide an integrative framework for the disciplinary and disparate mechanisms suggested by the development literature. The development literature on poverty traps can, in turn, provide detailed elaborations and substance to the three broader core characteristics of a social-ecological system from the resilience literature: potential, connectedness, and general system resilience. There are many similarities to be drawn between the two bodies of literature as they stand. The requirement for threshold levels of complementary capital for prosperity in the development literature fits well with the recognition of low potential or capital as one of the characteristics of poverty traps in the resilience literature. Dysfunctional institutions and the network effects of neighborhoods in the development literature also correspond to some degree with connectedness in the resilience literature. An issue to be resolved in synthesizing the two bodies of literature, however, is that although institutions and networks have been identified as the controlling variables that determine connectivity (Abel et al. 2006), connectedness as a result of dysfunctional or maladaptive institutions and networks in neighborhoods is not necessarily low.

Interpreting connectivity in terms of networks and institutions, or combining connectedness and potential as capital (Abel et al. 2006), may simplify and provide parsimony for analysis of a system's general resilience. However, this lumping of different core variables of a system can reduce a nuanced understanding of some of the nonsynchronous dynamics of the lumped elements that can be important for poverty and rigidity trap analyses. For example, bonding, linking, and bridging social networks form the structures of social capital and different levels and balances between these types of networks are required for different purposes (Maru and Davies 2011). Although bonding networks are essential for cohesion, collective action and maintaining strong shared norms and rules, closure as a result of strong and dense bonding networks without linking and bridging networks, can stifle innovation and the adoption of new ideas, and thereby prevent successful adaptation to changes in the system's environment. Likewise, cohesion and collective action can also suffer if there is no strong bonding and if most networks are with people outside the community (Maru et al. 2007).

The resilience literature identifies low general system resilience as part of the configuration of the core system properties that define a poverty trap. There is no corresponding concept or trap mechanism identified in the development literature. However, we note here that general system resilience is an emergent property (Maru 2010) that is largely dependent on the configuration and interaction of capital and connectedness (Maru 2010, Abel et al. 2006). Institutions and networks that form connectedness and capital are concepts that are familiar in the development literature.

Where the two bodies of literature diverge, they can, to some degree, assist in compensating for each other's weaknesses. Details describing the social mechanisms of poverty traps in the development literature can inform and expand specific models from the resilience literature (Carpenter and Brock 2008). The bias toward social explanations of poverty traps in the development literature supplements that toward biological explanations in the resilience literature. The inclusion of ecological and biological factors, as well as the linkage between traps with adaptive capacity to global perturbations such as climate change in the resilience literature, can assist in expanding examples from the development literature. We present two examples that deal with some of the weaknesses already identified by expanding the concept of a poverty trap from the development literature to consider simultaneous thresholds in multiple capitals, and the extension of a biological analogy from the resilience literature to explicitly embrace social factors.

\section{Expanding the development literature}

Figure 3 extends this development notion of a threshold level of well-being required to escape poverty by relating it to the underpinning levels of capital required to maintain well-being. Moreover, it represents the interactions between different types of capital, in this demonstration case for only two types of capital: physical capital and human capital, which are not always perfectly interchangeable in an economic sense. Like Barrett and Swallow's (2006) figure (see Fig. 1), there are two stable states to the system, but they are now defined by stable levels of these two forms of capital $\left(\mathrm{PC}_{\mathrm{L}}, \mathrm{HC}_{\mathrm{L}}\right)$ and $\left(\mathrm{PC}_{\mathrm{H}}\right.$, $\mathrm{HC}_{\mathrm{H}}$ ). Within the boundary of each basin, the interactions between the different levels of capital held by households in the socioeconomic system will tend to drive the system toward the stable state of that basin.

The critical transition between the two states defined by the unstable equilibrium is defined by the edge between the basins. In this hypothetical illustration, an individual, household, community, or nation can escape from the center of the impoverished basin of attraction, $\left(\mathrm{PC}_{\mathrm{L}}, \mathrm{HC}_{\mathrm{L}}\right)$ if they receive well-coordinated external support that: (1) increases their level of physical capital above the critical threshold $\mathrm{PC}_{\mathrm{C}}$, or (2) increases their level of human capital above the critical threshold $\mathrm{HC}_{\mathrm{C}}$. Importantly, the most effective mode of escape may require simultaneous threshold improvements in both factors to the point $\left(\mathrm{PC}_{\mathrm{C}}, \mathrm{HC}_{\mathrm{C}}\right)$ to reach a self-sustaining improved state. If an external perturbation can move a poor system beyond the edge between the basins into the unshaded basin of attraction, the system will then be driven by its internal 
Fig. 3. Figure 3(a) reproduces Barrett and Swallow's (2006) figure on well-being dynamics under the poverty trap hypothesis for comparison with the new extended figure provided in 3(b). Figure 3(b) generalizes the approach to multiple forms of capital, which interact to create two self-reinforcing stable states at different equilibrium levels of capital. Vitally, 3(b) illustrates that improvements to either human or physical capital alone may not provide the most effective transition from the impoverished state to the more desirable state.
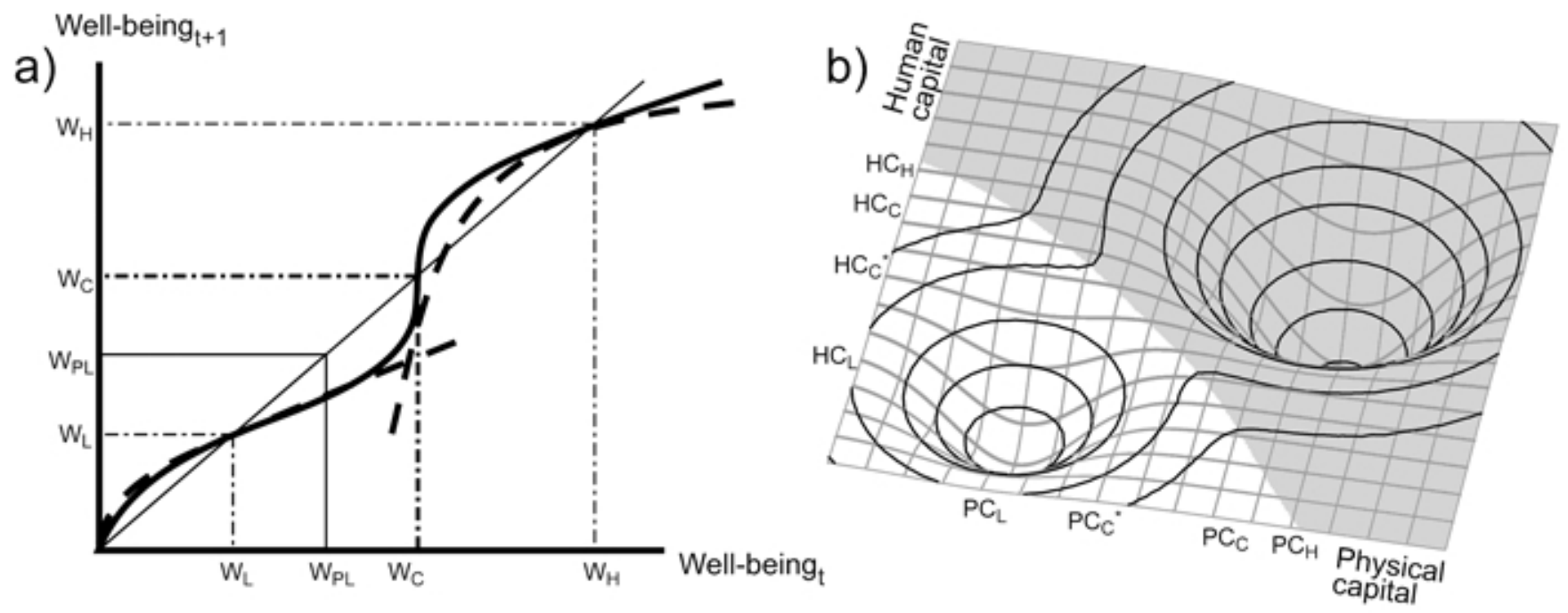

processes into the more productive state via a virtuous cycle, thereby escaping poverty. However, if external perturbations, such as aid or temporary welfare improvements, fail to reach the threshold levels required, the system will repeatedly collapse back to its poor state via a vicious cycle.

\section{Expanding the resilience literature}

Carpenter and Brock's (2008) model goes some significant way in articulating a general traps hypothesis on socialecological systems from a resilience perspective. However, by their own admission, it requires further refinement for application in specific scenarios. In indigenous systems, deeply entrenched social networks and institutions form a vital part of the identity and survival of the system, but at the same time may limit novel responses and create the potential for traps. Moreover, although Carpenter and Brock's analogy with allostasis emphasizes internal under-use of resources as a driver of poverty, lack of the threshold levels of capital for growth within some indigenous cultures may arise primarily from causes external to the system such as loss of land, loss of rights, and loss of individuals from the community to the wider system through historical colonial processes.

The most important extension to Carpenter and Brock's (2008) description, however, suggested by the synthesis of the development and resilience literature, is the potential for causal dynamics that may link rigidity and poverty traps in indigenous systems. That is, highly connected social networks and institutions in an indigenous social-ecological system, exacerbated by a history of negative interactions with and interventions from a larger colonial system, may lead to dynamics that simultaneously maintain high rigidity and reduce levels of various types of capital in the system, especially human capital, creating causally linked rigidity and poverty traps.

In Carpenter and Brock's (2008) original formulation, chronically low levels of stress correspond to an under-used system with unrealized or unutilized potential leading to a poverty trap. In the context of indigenous systems, this trap has two interpretations; it could arise because under-use of available potential (capital); but it could also result from a lack of capital or access to capital as is the case in disadvantaged systems. Chronically high levels of stress correspond to an over-used system unable to respond to external variability, caught in a rigidity trap. In between these two extremes, the system was neither under-used nor over-used and maintained a relatively high level of adaptive capacity. We can start to incorporate this synthesis of ideas into Carpenter and Brock's framework by extending their figure (Fig. 4a) along an axis of 'connectedness' (Fig. 4b). Taking insights from their paper, other parts of the resilience literature, and the development literature, we can make some simple observations.

At low levels of connectedness, individual parts of the system interact fairly independently, meaning the capacity of the 
Fig. 4. Figure 4(a) reproduces Carpenter and Brock's (2008) figure relating adaptive capacity, A(S), to stress, S, for direct comparison to the new, extended figure provided in 4(b). Figure 4(b) incorporates insights from other resilience and development literature perspectives to extend Carpenter and Brock's original model along a new axis of connectedness, C. The location of the original figure is indicated by the heavy line at $C=5$. As connectedness increases, the performance of disparate parts of the system is bound together more tightly and the transitions between the 'rigidity trap,' 'adaptive capacity, ' and 'poverty trap' regions become more abrupt. At very low levels of connectedness a rigidity trap of the sort described in the resilience literature is not possible.

a)

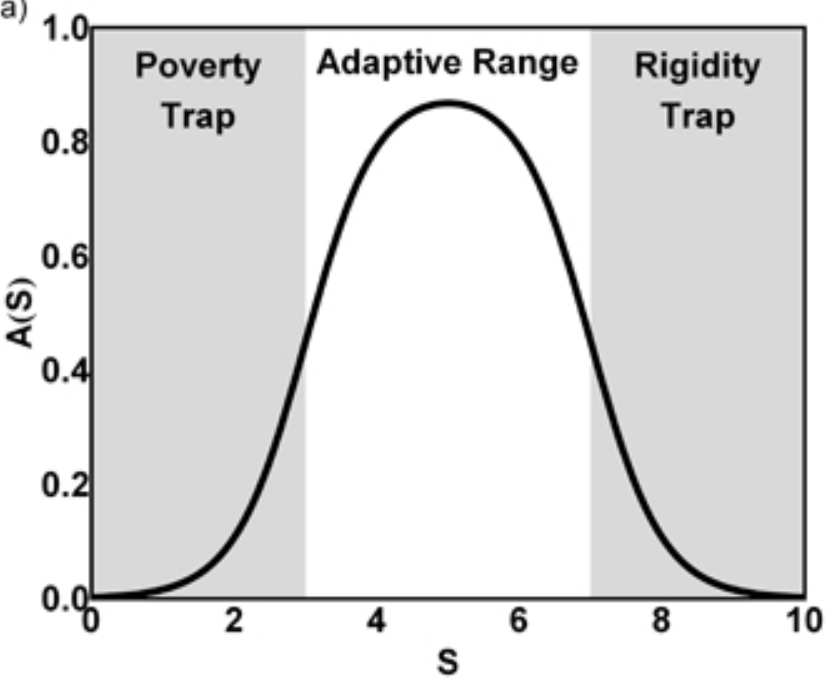

b)

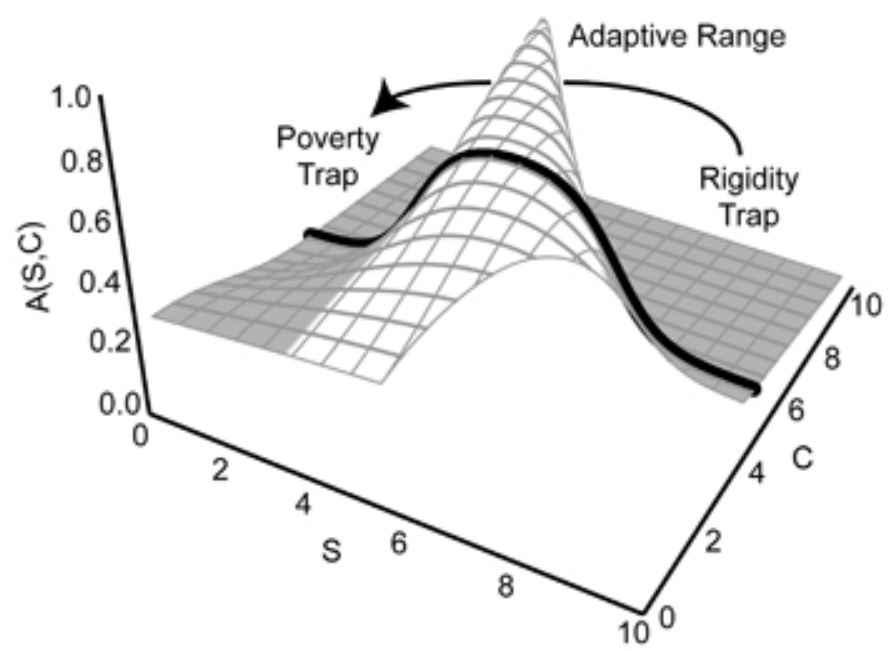

system to explore is high, but capacity of the system to focus resources at a large scale is low. From a disadvantage perspective, individuals may 'expend effort to adapt' and, indeed, some may succeed, but they do so independently, so progression across the system as a whole is gradual. Total adaptive capacity is effectively the sum of the individual parts, and neither the depths of the poverty trap, nor the heights of a well-adapted system will be as extreme as a more connected system. As connectedness nears zero the potential for a rigidity trap of the type identified in the literature no longer exists.

At high levels of connectedness, individual parts of the system are interlinked by dense and strong networks, norms, and rules (institutions). This leads to a rigidity trap when there is corresponding high level of holding and use of capital that often only benefits those linked. In a well-adapted system, moderate levels of networks and institutions, coupled with accessible capital, may interact to ensure that if individual parts of the system temporarily fall into poverty, they can be supported by other parts to escape trap-like dynamics. However, it is equally true that for systems that are, as a whole, already in poverty because of low access or effective utilization of potential, the same rigid norms and rules supported by dense and strong networks may act to pull individual components of the system 'expending effort to adapt' back into disadvantage. The net effect is that the threshold between the high adaptive capacity parts of Carpenter and Brock's (2008) curve and the 'traps,' or low adaptive capacity parts of the curve, will get more abrupt. For well-adapted systems, connectedness may increase the total adaptive capacity of the system to significantly greater than the sum of the individual parts, but for systems already trapped, this same process may reduce the adaptive capacity of the system as a whole. Finally, as connectedness becomes very high, the peak in adaptive capacity becomes very high, but across a vanishingly small set of stress conditions.

It is possible to envision a scenario in which a system, as a whole, is caught in either a poverty trap or a rigidity trap. However, it is also possible to envisage a scenario in which two or more subsystems of a focal system exhibit poverty and rigidity trap dynamics such that they reinforce each other via casual links, as shown by the arrow in Figure 4. For example, a disadvantaged indigenous system may have a high level of connectedness developed as part of a cultural identity of high bonding and reciprocity networks and strictly observed customary norms and rules, amplified in response to hostile political and socioeconomic environments. These high levels of connectedness, combined with low levels of access to capital and a hostile political and socioeconomic environment, 
can result in a poverty trap. Moreover, a nonindigenous component of the system may exhibit rigid dynamics, evolved to efficiently amass resources by implementing rigid networks and institutions, which may intentionally or unintentionally exclude indigenous peoples from effective access to resources and opportunities.

This model captures the potential causal link between rigidity traps and poverty traps and suggests a need for rethinking of the definitions and links of poverty and rigidity traps. Like Carpenter and Brock's (2008) original framework, the extension we have presented is not intended to be a detailed model, but instead to provide a foundation for thinking about how trap dynamics in indigenous systems may play out to make efforts at escaping poverty and disadvantage highly nonlinear affairs.

\section{Remaining challenges}

The comparative review and the initial synthesis exercise attempted in this paper provide insights and direction for further work in developing integrated trap frameworks applicable in different contexts. Such work needs to address at least three crucial challenges to be applicable in investigating traps in the context of indigenous people in developed countries.

The first challenge is the need to account for the intended and unintended consequences of a legacy of colonial power relations. This challenge will manifest itself in how we bound the system around the issue of persistent indigenous poverty and disadvantage, characterize the system-environment interaction, and identify both the internal and external causes of persistent poverty and disadvantage.

In the poverty trap literature there has been a tendency to technicalize issues of poverty. However, power and political issues need not be neglected because they are less amenable to technical analysis. In the indigenous context the consequences of power relations should be part of the analysis of the persistence of poverty and disadvantage. A system bounded narrowly around indigenous livelihoods in investigating poverty traps will fail to account for the legacy of power relations. Since colonization the lives and livelihoods of most indigenous people have not been entirely private. They have been subject to several interventions in the forms of policies and programs (Cornell 2005) that may lead to causes distant in time, space, and social organization (Forrester 1994).

To explore the causal mechanisms of traps from a systems perspective, one also requires a careful characterization of the relationship between the system in focus with its environment as well as its host- and subsystems. The typical characterization of the relationships between nested systems from the resilience literature is that "each scale operates at its own pace, protected from above by slower, larger levels, but invigorated from below by faster, smaller cycles of innovation" (Holling 2001:398-399). This may not always be the case: for example, in systems such as in indigenous Australia, where the historical colonial system that superimposed itself at a larger scale neither protected nor provided memory and seed for renewal. Instead, it often dispossessed the colonized system and quashed any revolt and innovation that came from it. In studying the nature of traps in indigenous settings, the legacy and remnants of such hostile political and economic relationships between systems and scales should be part of the analysis.

Systems thinking advises that it is important to look for endogenous causes of problems, and cautions that people often fail to do so (e.g., Senge 1992, Sterman 2000). Both the resilience and development literature also heavily focus on the internal limitations of the system in question, either in the form of adaptive failure or neighborhood or peer effects. Although internal causes for indigenous poverty and disadvantage need to be examined, accounting for external causes that are distant in time, place, and social organization will be an important and significant challenge for systems approaches.

The second insight that challenges the current interpretation of poverty traps is that rather than being a product of low resilience, traps may in fact be highly resilient but undesirable system states. A system in a poverty trap is resilient to efforts by individuals, communities, and governments to provide the means of escape. This interpretation of poverty traps as perverse resilience challenges the normative view of resilience, i.e., its current use in characterizing poverty traps as having low general system resilience, as well as the simplistic but pervasive perspective that resilience is always a good thing. This normative view persists despite the fact that resilience, in and of itself, is neither good nor bad, and warnings from the literature that in certain circumstances resilience of an undesirable state can be a bad thing (Walker et al. 2004, Maru 2010).

The configurations and interactions of capital and connectedness play a crucial role in generating and maintaining high resilience, which is a problem if the system is in an undesirable state. However, the drivers of this resilience may not be entirely internal to the system. At least in the case of marginalized indigenous systems, this resilience can also be understood as a result of legitimate intransigence arising from the social impacts of colonization. Indigenous systems can act to resist the colonizing effects of government and market institutions, based on past experiences of prolonged injustices and ensuing mistrust. Indigenous livelihood systems can resist policies in an attempt to preserve aspects of life such as language, culture, and ceremonial obligations, which, if affected, can threaten their indigenousness. Although such a response to hostile socioeconomic and political environments may help maintain 
distinct identity, they may lead to further livelihood issues and contribute to poverty in many other spheres of life.

Importantly, this observation does not imply that indigenous people must abandon the networks and institutions that are important for high connectedness to escape a poverty trap. Rather, it suggests that escaping a poverty trap would involve a complex set of trade-offs as indigenous people seek support from and engage with established mainstream economies that operate with different sets of values, norms, and rules that, in turn, underpin principles such as privatization and the centrality of the individuals and individualism as drivers of economic growth. Although understanding and resolving poverty traps will be a major component of sustainable indigenous development, it is beyond the scope of this paper to discuss which development approaches would allow indigenous people to understand and decide on trade-offs involved in the adopting and adapting new sets of institutions and networks for development, while limiting negative impacts on the values and norms that constitute their identity. However, this is an important area that will need to be investigated further, given that many indigenous people in poverty have strong collective norms for sharing and histories that differ from the nonindigenous poor. In another article, Maru and Chewing (2011) have made a preliminary exploration of Sen's (1999) proposition of 'development as freedom' as a candidate to be adapted to indigenous development contexts. Sen interprets development as expanding capability, an ability to be and do what people have reason to value (Sen 1997). Although important, indigenous development should not be entirely about having the capacity to successfully engage with mainstream economic activities. It should also be about developing successful livelihood options that allow indigenous people to do and be what they value with what they have, including their knowledge, institutions, and connections among themselves and with their land, attributes that will be vital for sustainable development of social-ecological systems.

The third insight that challenges current understanding of traps is that in the indigenous context where marginalization still continues, rigidity and poverty traps may coexist and indeed be causally linked. We have explored how a hostile relationship between nested social-ecological systems may lead to such a phenomenon. The dispossession that goes along with colonization can set the initial conditions for poverty traps in the colonized system and possibly reinforce its persistence through a hostile relationship between the colonized and the colonizing system. Those who appropriate resources may develop a rigidity trap with high connectivity of networks and inflexible institutions that lock out certain groups from having access to economic opportunities. These locked-out groups are then more likely to find themselves in a poverty trap situation. Furthermore, although physical hostilities and dispossession may have ceased long ago, the imposition and conflict between values and norms still continues, creating significant barriers for indigenous livelihood improvement. The co-occurrence of poverty and rigidity traps may not be restricted to social-ecological systems: a patho-physiological example can be found in the co-occurrence and causal link between obesity (poverty trap) and hypertension (rigidity trap) among many adults in the USA (Sterling 2004).

\section{CONCLUSION}

Persistent and tightly linked disadvantage and poverty among many indigenous groups in developed countries are indicative of traps. A systems approach that can synthesize the current broad typologies of traps in the resilience literature with the detailed and rich understanding of the mechanisms of poverty traps from the development literature will certainly advance our understanding of persistent poverty and disadvantage in both indigenous and nonindigenous contexts. In this paper we have sketched out the initial steps of this systemic synthesis. Further synthesis work is required to develop an integrated framework that will need to account for insights and challenges arising from the indigenous poverty and disadvantage context including an explicit characterization of indigenous systemenvironment interactions and an awareness of the possibility of complementary poverty and rigidity traps as well as the recognition of the possibility of poverty traps as resilient but undesirable states. Understanding and resolving the nonlinear state of persistent poverty and disadvantage may well be the first step toward indigenous development, but long-term sustainable indigenous development will need to explore new approaches that focus not only on capital, but also on capability building, the ability for indigenous people to be and do what they value with what they have.

Responses to this article can be read online at: http://www.ecologyandsociety.org/vol17/iss2/art7/responses/

\section{Acknowledgments:}

We appreciate the comments by internal CSIRO reviewers Ashley Sparrow and Jocelyn Davies. We are also grateful to insightful comments and suggestions from two anonymous reviewers, which helped us to substantially improve the structure and content of the article.

\section{LITERATURE CITED}

Abel, N., D. H. M. Cumming, and J. M. Anderies. 2006. Collapse and reorganization in social-ecological systems: questions, some ideas, and policy implications. Ecology and Society 11(1): 17. [online] URL: http://www.ecologyandsociety. org/vol11/iss1/art17/ 
Adger, W. N. 2006. Vulnerability. Global Environmental Change 16(3):268-281. http://dx.doi.org/10.1016/j.gloenvcha .2006 .02 .006

Allison, H. E., and R. J. Hobbs. 2004. Resilience, adaptive capacity, and the "Lock-in Trap" of the Western Australian agricultural region. Ecology and Society 9(1): 3. [online] URL: http://www.ecologyandsociety.org/vol9/iss1/art3/

Altman, J. C. 2000. The economic status of Indigenous Australians. CAEPR Discussion Series no. 193/2000. Centre for Aboriginal Economic Policy Research, Australian National University, Canberra, Australia.

Altman, J. C., N. Biddle, and B. H. Hunter. 2009. Prospects for "closing the gap" in socioeconomic outcomes for Indigenous Australians? Australian Economic History Review 49(3):225-251. [online] URL: http://www3.interscience.wiley. com/cgi-bin/fulltext/122666567/PDFSTART

Armitage, A. 1995. Comparing the policy of Aboriginal assimilation: Australia, Canada, and New Zealand. University of British Columbia Press, Vancouver, British Columbia, Canada.

Australian Institute of Health and Welfare. 2008. Australia's health 2008. Cat. no. AUS 99. AIHW, Canberra, Australia.

Azariadis, C., and J. Stachurski. 2005. Poverty traps. Pages 295-384 in P. Aghion and S. Durlauf, editors. Handbook of economic growth. Elsevier, Amsterdam, The Netherlands. http://dx.doi.org/10.1016/S1574-0684(05)01005-1

Barrett, C. B., and B. M. Swallow. 2006. Fractal poverty traps. World Development 34(1):1-15. http://dx.doi.org/10.1016/j.w orlddev.2005.06.008

Bird, K. 2007. The intergenerational transmission of poverty: Aan overview. CPRC Working Paper 99. Chronic Poverty Research Centre, London, UK.

Bowles, S., S. N. Durlauf, and K. R. Hoff. 2006. Poverty traps. Princeton University Press, Princeton, New Jersey, USA.

Brooks, N. 2003. Vulnerability, risk and adaptation: a conceptual framework. Working Paper No. 38, Tyndall Centre for Climate Change Research and Centre for Social and Economic Research on the Global Environment, University of East Anglia, Norwich, UK.

Carpenter, S. R., and W. A. Brock. 2008. Adaptive capacity and traps. Ecology and Society 13(2): 40. [online] URL: http: //www.ecologyandsociety.org/vol13/iss2/art40/

Carter, M. R., and C. B. Barrett. 2006. The economics of poverty traps and persistent poverty: an asset-based approach. Journal of Development Studies 42(2):178-199. http://dx.doi. org/10.1080/00220380500405261
Carter, M. R., and J. May. 1999. Poverty, livelihood and class in rural South Africa. World Development 27(1):1-20. http://d x.doi.org/10.1016/S0305-750X(98)00129-6

Carter, M. R., and J. May. 2001. One kind of freedom: poverty dynamics in post-apartheid South Africa. World Development 29(12):1987- 2006. http://dx.doi.org/10.1016/S0305-750X(01) 00089-4

Collier, P. 2007. Poverty reduction in Africa. Proceedings of the National Academy of Sciences 104:16763-16768. http://d x.doi.org/10.1073/pnas.0611702104

Cornell, S. 2005. Indigenous peoples, poverty, and selfdetermination in Australia, New Zealand, Canada, and the United States. Pages 199-225 in R. Eversole, J. A. McNeish, and A. D. Cimadamore, editors. Indigenous peoples and poverty: an international perspective. Zed Books, London, UK.

Dasgupta, P. 2007. Nature and the economy. Journal of Applied Ecology 44(3):475-487. http://dx.doi.org/10.1111/j.1 365-2664.2007.01316.x

Davies, S. 1996. Adaptable livelihoods. Macmillan, London, UK.

Engerman, S. L., and K. L. Sokoloff. 2006. The persistence of poverty in the Americas: the role of institutions. Pages 43-78 in S. Bowles, S. N. Durlauf, and K. Hoff, editors. Poverty traps. Princeton University Press, Princeton, New Jersey, USA.

Eversole, R., J. A. McNeish, and A. D. Cimadamore, editors. 2005. Indigenous peoples and poverty: an international perspective. Zed Books, London, UK.

Forrester, J. W. 1994. Learning through systems dynamics as preparation for the 21st century. Keynote Address for Systems Thinking and Dynamic Modelling Conference for K-12 Education. Concord Academy, Concord, Massachusetts, USA.

Hall, G., and H. A. Patrinos. 2005. Indigenous peoples, poverty and human development in Latin America. Palgrave, London, UK. http://dx.doi.org/10.1057/9780230377226

Hall, G., and H. A. Patrinos, editors. 2010. Indigenous peoples, poverty and development. World Bank, Washington, D.C., USA.

Hoff, K., and A. Sen. 2006. The kin system as a poverty trap? Pages 95-115 in S. Bowles, S. N. Durlauf, and K. Hoff, editors. Poverty traps. Princeton University Press, Princeton, New Jersey, USA.

Holling, C. S. 2001. Understanding the complexity of economic, ecological, and social systems. Ecosystems 4:390405. http://dx.doi.org/10.1007/s10021-001-0101-5 
Holling, C. S., and L. H. Gunderson. 2002. Resilience and adaptive cycles. Pages 25-62 in C. S. Holling and L. H. Gunderson, editors. Panarchy: understanding transformations in human and natural systems. Island Press, Washington, D. C., USA.

Holling, C. S., L. H. Gunderson, and G. D. Peterson. 2002. Sustainability and panarchies. Pages 63-102 in C. S. Holling and L. H. Gunderson, editors. Panarchy: understanding transformations in human and natural systems. Island Press, Washington, D.C., USA.

Hyden, G. 2007. Governance and poverty reduction in Africa. Proceedings of the National Academy of Sciences 104:16751-16756. http://dx.doi.org/10.1073/pnas.0700696104

International Work Group for Indigenous Affairs (IWGIA) 2008. The indigenous world 2008. Transaction, Edison, New Jersey, USA.

Kates, R. W., and P. Dasgupta. 2007. African poverty: a grand challenge for sustainability science. Proceedings of the National Academy of Sciences 104:16747-16750. http://dx.do i.org/10.1073/pnas.0708566104

Leventhal, T., and J. Brooks-Gunn. 2000. The neighborhoods they live in: the effects of neighborhood residence on child and adolescent outcomes. Psychological Bulletin 126 (2):309-337. http://dx.doi.org/10.1037//0033-2909.126.2.309

Lewis, K., and S. Burd-Sharps. 2010. The measure of America 2010-2011: mapping the risks and resilience american human development project. New York University Press, New York, New York, USA.

Maru, Y. T. 2010. Resilient regions: clarity of concepts and challenges to systemic measurement. CSIRO SocioEconomics and the Environment in Discussion (SEED) Working Paper Series 2010-04, CSIRO, Canberra, Australia. [online] URL: http://www.csiro.au/Outcomes/Environment/P opulation-Sustainability/ /media/CSIROau/Divisions/CSIRO\% 20Sustainable\%20Ecosystems/SEEDPaper41 CSE pdf\%20Standard. pdf

Maru, Y. T., and V. H. Chewings. 2011. A review of measurement and causal analysis of Indigenous poverty and disadvantage in remote Indigenous Australia. CSIRO SocioEconomics and the Environment in Discussion (SEED) Working Paper Series Number 2011-02, CSIRO, Canberra, Australia. [online] URL: http://www.csiro.au/Organisation-S tructure/Divisions/Ecosystem-Sciences/ /media/CSIROau/Divisions/ CSIRO\%20Ecosystem\%20Sciences/SEEDPaper44 CES pdf\% 20Standard.pdf

Maru, Y. T., and J. Davies. 2011. Supporting cross-cultural brokers is essential for employment among Aboriginal people in remote Australia. Rangeland Journal 33:327-338.
Maru, Y. T., R. R. J. McAllister, and M. Stafford Smith. 2007. Modelling community interactions and social capital dynamics: the case of regional and rural communities of Australia. Agricultural Systems 92(1-3):179-200. http://dx.doi. org/10.1016/j.agsy.2006.03.005

Moran, A. 2002. As Australia decolonizes: indigenizing settler nationalism and the challenges of settler/indigenous relations. Ethnic and Racial Studies 25(6):1013-1042. http://dx.doi.org $\underline{110.1080 / 0141987022000009412}$

Myrdal, G. 1957. Economic theory and under-developed regions. Gerald Duckworth, London, UK.

Nurske, R. 1953. Problems of capital formation in underdeveloped areas. Oxford University Press, New York, New York, USA.

Pebley, A. R., and N. Sastry. 2004. Neighborhoods, poverty, and children's well-being. Pages 119-145 in K. M. Neckerman, editor. Social inequality. Russell Sage Foundation, New York, New York, USA.

Rosenstein-Rodan, P. 1984. Natura facit saltum: analysis of the disequilibrium growth process. Pages 207-221 in G. Meier and D. Seers, editors. Pioneers in development. Oxford University Press, New York, New York, USA.

Sampson, R. J., and J. D. Morenoff. 2006. Durable inequality. Pages 176-203 in S. Bowles, S. N. Durlauf, and K. Hoff, editors. Poverty traps. Princeton University Press, Princeton, New Jersey, USA.

Sampson, R. J., J. D. Morenoff, and T. Gannon-Rowley. 2002. Assessing "neighborhood effects": social processes and new directions in research. Annual Review of Sociology 28 (1):443-478.

Sarche, M., and P. Spicer. 2008. Poverty and health disparities for American Indian and Alaska Native children: current knowledge and future prospects. Annals of the New York Academy of Sciences 1136(1):126-136. http://dx.doi.org/10.1 196/annals.1425.017

Scheffer, M., and F. R. Westley. 2007. The evolutionary basis of rigidity: locks in cells, minds, and society. Ecology and Society 12(2): 36. [online] URL: http://www.ecologyandsociety. org/vol12/iss2/art36/

Steering Committee for the Review of Government Service Provision (SCRGSP). 2011. Overcoming Indigenous disadvantage: key indicators 2011. Productivity Commission, Canberra, Australia. [online] URL: http://www.pc.gov.au/gsp/ indigenous/key-indicators-2011

Sen, A. 1997. Editorial: human capital and human capability. World Development 25(12):1959-1961. http://dx.doi.org/10.1 016/S0305-750X(97)10014-6

Sen, A. 1999. Development as freedom. Oxford University Press, New York, New York, USA. 
Senge, P. M. 1992. The fifth discipline: the art and practice of the learning organization. Random House, Sydney, Australia. http://dx.doi.org/10.1002/pfi.4170300510

Sterling, P. 2004. Principles of allostasis: optimal design, predictive regulation, pathophysiology and rational therapeutics. Pages 17-64 in J. Schulkin, editor. Allostasis, homeostasis, and the costs of physiological adaptation. Cambridge University Press, Cambridge, UK.

Sterman, J. D. 2000. Business dynamics: systems thinking and modeling for a complex world. McGraw Hill, New York, New York, USA.

Stewart, F. 2009. Horizontal inequality: two types of trap. Journal of Human Development and Capabilities 10 (3):315-340. http://dx.doi.org/10.1080/19452820903041824

Turner, B. L., R. E. Kasperson, P. A. Matson, J. J. McCarthy, R. W. Corell, L. Christensen, N. Eckley, J. X. Kasperson, A. Luers, M. L. Martello, C. Polsky, A. Pulsipher, and A. Schiller. 2003. A framework for vulnerability analysis in sustainability science. Proceedings of the National Academy of Sciences 100:8074-8079. http://dx.doi.org/10.1073/pnas.1231335100

United Nations Development Programme (UNDP). 2009. Human development report 2009. Overcoming barriers: human mobility and development. UNDP, New York, New York, USA. [online] URL: http://www.unher.org/refworld/do cid/4ac9d10d2.html

Walker, B., C. S. Holling, S. R. Carpenter, and A. Kinzig. 2004. Resilience, adaptability and transformability in socialecological systems. Ecology and Society 9(2): 5. [online] URL: http://www.ecologyandsociety.org/vol9/iss2/art5/

Wilson, D., and D. MacDonald. 2010. The income gap between Aboriginal peoples and the rest of Canada. Canadian Centre for Policy Alternatives, Ottawa, Ontario, Canada. [online] URL: http://www.policyalternatives.ca/publications/reports/incomegap-between-aboriginal-peoples-and-rest-canada

Wilson, W. J. 1987. The truly disadvantaged: the inner city, the underclass, and public policy. Pages 186-192 in G. Bridge and S. Watson, editors. The blackwell city reader. Blackwell, Chicago, Illinois, USA.

Yap, M., and N. Biddle. 2010. Gender gaps in Indigenous socioeconomic outcomes: Australian regional comparisons and international possibilities. International Indigenous Policy Journal 1(2):3. [online] URL: http://ir.lib.uwo.ca/iipj/ vol1/iss $2 / 3 /$

Young, A. A. 1928. Increasing returns and economic progress. Economic Journal 38(152):527-542. http://dx.doi.org/10.230 7/2224097
Young, E. 1995. Third world in the first: development and indigenous peoples. Routledge, London, UK. 